\title{
Integrated Quality Function Deployment (QFD) Model for Dry Bulk Terminal Improvements (DBTI) in Malaysian Ports
}

\author{
Md. Ashlyzan Razik, Razman Mat Tahar, Wan Hasrulnizzam Wan Mahmood, and Norlinda Mohd Rozar
}

\begin{abstract}
The main purpose of this paper is to apply integrated quality function deployment (QFD) for dry bulk terminal improvement from the perspectives of the customers. Firstly, the main issue of the QFD problem was made which are 'what' the customer required and 'how' to implement the problem to solutions. This two major of components to be emphasized on the house of quality (HOQ) matrices. In this research, the systematic procedures using inferential statistics which are factor analysis and correlation spearman were applying in QFD method. Factor analysis used for identifying the best group and reduced the unused items. Whereas correlation spearman used for see the relationship and strengthen each factor. The results in this study show 4 best group or criteria were identified which are loading efficiency, infrastructure improvement, time performance and dry bulk operation improvement. This four criteria is the main criteria for improvement. The using QFD method suggested the management in Port Terminal should listen the customer voice to raise the issue for solutions. How to solve the issue is based on the strategy implemented. The proposed strategy from this study can be used for the port management to identify solution in dry bulk terminal.
\end{abstract}

Index Terms-Quality function deployment (QFD), dry bulk terminal improvement (DBTI), house of quality (HOQ).

\section{INTRODUCTION}

Dry bulk sector is the single largest commodity grouping in terms of tons loaded in the context of international seaborne trade.

Fig. 1 shows the International Seaborne Trade that represented $38 \%$ of global seaborne tones, followed by oils $34 \%$ and containerized cargo $28 \%$. This trade divided two categories which is major dry bulk and minor dry bulk. Iron ore contributed two third of major dry bulk volume which is accounting for 844 million tons, coal, 815 million tons, grain 323 million tons, bauxite and alumina 84 million tons and phosphate rock 32 million tons. In contrast, minor dry bulk consist of a wide variety of cargo types which to be shipped in smaller quantities still represent important trades. This is proved in 2011 over 265 million tons of steel was loaded, 176 million tons of forestry products, 83 million tons of bulk fertilizers, 120 million tons of cement and clinker and 519 million tons of raw sugar [1].

The high demand from around the world on dry bulk sector, causing pressure on the terminals to increase their capacity. Many dry bulk terminals around the world are

Manuscript received October 18, 2013; revised December 20, 2013.

Muhammad Ashlyzan Bin Razik is with the Universiti Malaysia Pahang, Malaysia (e-mail: arazik77@yahoo.com). expanding and seriously increasing their capacity due to the high demand for energy and mineral resources [2]. To reach for these purposes, the existing terminal must take the challenge to improve their efficiency through making an investment. It takes into account what and how parts aspects in dry bulk terminals to improved. Some port authority used the approach to expand the port using by copying the existing facilities until the required capacity is reached. In other words, the terminal does not only lose the opportunity to utilize the developments which made over the last decades on terminal design but also end up with a costly operation. And apart from that, every port authority must be careful in making investment considerations which would like to do. Hence, for the port authority, must consider how to develop an efficient marine terminal to create significantly value added benefits for the customers [3].

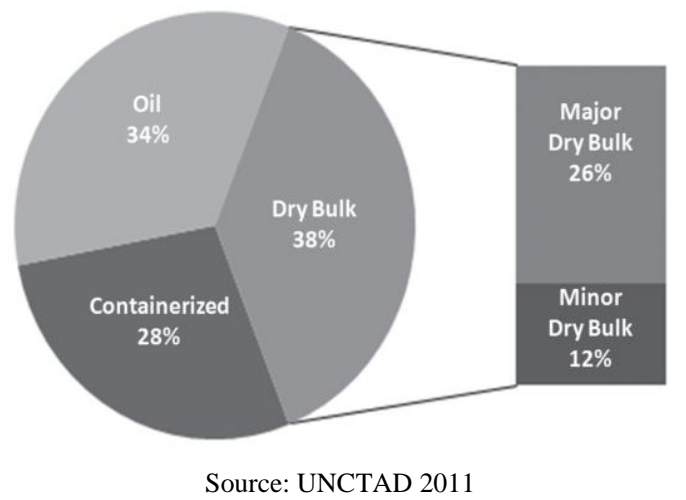

Fig. 1. International seaborne trade.

From the perspective of Port Management and authority especially in Dry Bulk Terminals, they have information and feedback about the criteria needed from port users or customers such as what requirement is needed to improve the port and how to become competitive. This information is very important as input to design and where to improve. Apart from that, quality function deployment (QFD) is a suitable approach to explain this circumstance. The QFD is a theory from total quality management (TQM) and its function to identify customer requirements and assure quality in dry bulk terminal improvement (DBTI). Other than that, inferential statistics such as factor analysis used for grouping the WHATs priority and correlation spearman used for correlation each factor in house of quality (HOQ). HOQ shows the matrices used for relationship between customer's requirement ('what' customer needs) and technical specifications or design requirements ('how' the products/services have to be made) [3]. The matrices of 
HOQ are used for organizing customers' requirement and establishing priorities of technical specifications to satisfy customer requirements [4]. Integrated QFD and inferential statistics such as factor analysis and correlation spearman hoping can identify the solutions in Dry Bulk Terminals Improvements for Malaysians Ports.

In summary, the main purpose of this paper to apply the integrated QFD model to identify solutions for Dry Bulk Terminals Improvements in Malaysian Port. Section I provides some background information of this issue. Next sections are research methodology, procedures and analysis. Finally, some conclusions are made in last section.

\section{RESEARCH Methodology}

From Fig. 2, the design of the study began with the identification of the problem and objectives of the study. It also involves the study of literature includes studies secondary data obtained. Next, the literature review to be fine-tuned instrument including a questionnaire. The study concludes with a summary and some suggestions for future researches are also involved two data collection methods, namely, (a) survey, and (b) case study.



Fig. 2. The flow process of research methodology used for this paper.

Survey that aims to get the requirement needed for dry bulk terminal improvement (DBTI) for all ports in Malaysia. The total numbers of Ports involved in this survey are 18 . There are a lot of literatures to prove that the survey is a major contributor to Ports findings [3] - [9]. This is because the cost is low and prejudiced responses can be minimized due to the influence of the interviewer [10]-[11]. In fact, it is the most economical method of data collection methods for large groups [12]. Results of this study are used for development Quality Function Deployment(QFD) Model.
The case study research method is implemented to explore in more detail the question of WHATs and HOWs [13]. In this study, the research question, "What should Dry bulk terminal have to improve?" And "How QFD Methods implementation can improve the performance of the DBTI?" Became the main focus of the study. This study involves a number of qualitative research data collection methods included unstructured interviews, observation, simulation, and review of documents such as research [14]-[16]. In Malaysia, there are 18 ports where contribute $98 \%$ volumes total of cargo [17]. The literature review found fewer still focused research in DBTI especially in Malaysia.

\section{QFD DEVELOPMENT AND RESULTS}

In this analysis, there are seven steps to complete the House of Quality (HOQ) for Dry Bulk Terminal Improvement (DBTI) as follow in Fig. 3. There are:

- Step 1: Room 1 The List of Customer Requirement (WHATs )

- Step 2: Room 2 The List of Technical Descriptor (HOWs)

- Step 3: Room 3 Relationship Matrix

- Step 4: Room 4 Develop an interrelationship matrix between HOWS

- Step 5: Room 5 Develop an interrelationship between WHATS

- Step 6: Room 6 Technical Competitive Assessmen

- Step 7: Room 7 Priorities for improvement.

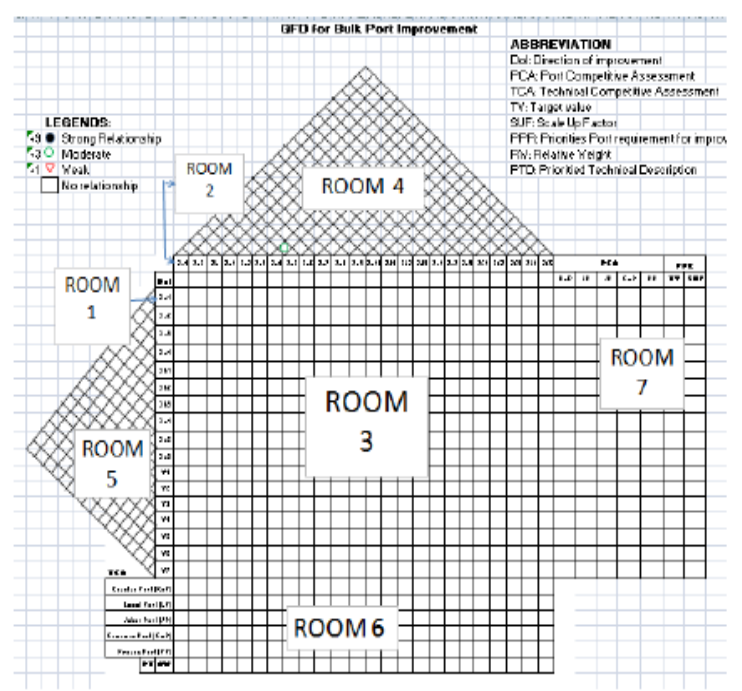

Fig. 3. QFD proposed model.

The HOQ's first room are known as customer requirements(CR) which is concern about the voice of customer that a structured list of requirements due to product and attributes as the customer describe them, together measure of the importance the customers attach to each requirement. The list is often referred as the WHATs that a customer needs or expects in a particular products or improvements. This list of primary customer requirements is usually vague and very general in nature. The secondary customer requirement is explaining the greater detail than those on the list of primary customer requirements; they are often not directly actionable by the engineering department 
and need further definition. The CR was calculated from the survey for total 18 ports around Malaysia. By using factor analysis, there are 4 priority group chosen such as loading efficiency, infrastructure improvements, time performance and operation improvement. Fig. 4 shows the list of primary, secondary and abbreviations for each element. All these elements are to be used during build HOQ.

\begin{tabular}{|l|l|}
\hline Primary & Secondary \\
\hline Loading Efficiency & Loading cost reduction \\
& Xa1 \\
\cline { 2 - 2 } & Trucking efficiency improvement \\
Xa2 \\
\cline { 2 - 3 } & Loading Work-in-process reduction \\
Xa3
\end{tabular}

Fig. 4. The list of customer requirement.

Step 2 or room 2 is the list of technical descriptors. Technical descriptor is to design and change the design of a product or services in a way to meets or exceeds the customer expectations. In this analysis the QFD team must come up with engineering characteristics or technical descriptors (HOWs) that will affect one or more of the customer requirements (WHATs). In other words, its likes to make up the ceiling or second floor of the house of quality (HOQ). These engineering characteristics must directly affect a customer perception and be translated in measurable terms. Same with customer requirements, the technical descriptors is divided into a hierarchy of primary and secondary. The primary technical descriptors are accomplished by defining a list of secondary technical descriptors that represent greater detail than primary technical descriptors. This process is similar to translating system level engineering specifications into part level specifications. Fig. 5 shows the all elements in technical descriptors

Room 3 is to building a HOQ which to compare between customer requirements (WHATs) and technical(HOWs) descriptors to determine the relationship. The symbols are used to describe the strength of the relationship as follows:

Legends:

$$
\begin{array}{ll}
\text { +9 } & \text { Strong Relationship } \\
+3 & \bigcirc_{\text {Moderate }} \\
+1 & \nabla \text { Weak } \\
& \square \text { No relationship }
\end{array}
$$

Room 4 or the roof of the HOQ which to identify any interrelationships between each technical descriptors. In other words to determine HOWs vs. HOWs.

Room 5 is to identify customer requirements between customer requirements or WHATs vs WHATs.

Room 6 is to identify the Technical Competitive Assessment(TCA). This study had chosen 5 ports such as Kuantan Port, Lumut Port, Johor Port, Kemaman Port and Penang Port. All these ports selected for testing the models. These TCA contains prioritized technical descriptors (PTD) and absolute weight that most needed to fulfill customer requirements and need improvement.

\begin{tabular}{|c|c|c|}
\hline Primary & Secondary & $\begin{array}{l}\text { Abbrevi } \\
\text { ations }\end{array}$ \\
\hline \multirow[t]{2}{*}{ Utilization } & Labour & Za1 \\
\hline & Machine & $\mathrm{Za} 2$ \\
\hline Berth & Berth size & $\mathrm{Zb}$ \\
\hline \multirow{10}{*}{$\begin{array}{l}\text { Materials } \\
\text { Handling Facilities }\end{array}$} & Bucket wheel loading & $\mathrm{Zc1}$ \\
\hline & Clamshell grabs & $\mathrm{Zc} 2$ \\
\hline & Loading spouts & $\mathrm{Zc} 3$ \\
\hline & Mobile Harbor cranes & $\mathrm{Zc} 4$ \\
\hline & Conveyor & Zc5 \\
\hline & $\begin{array}{ll}\text { Conventional labour } \\
\text { oriented }\end{array}$ & Zc6 \\
\hline & Pipelines & Zc7 \\
\hline & Grabs & Zc8 \\
\hline & Hooper & Zc9 \\
\hline & cranes & $\mathrm{Zc10}$ \\
\hline \multirow{3}{*}{$\begin{array}{l}\text { Transportation For } \\
\text { Moving cargo }\end{array}$} & Lorry & $\mathrm{Zd1}$ \\
\hline & Truck & $\mathrm{Zd} 2$ \\
\hline & Railway & $\mathrm{Zd} 3$ \\
\hline \multirow{3}{*}{$\begin{array}{l}\text { Trucking } \\
\text { Efficiency }\end{array}$} & Less than 15 minutes & Ze1 \\
\hline & Between 15-30 minutes & Ze2 \\
\hline & Upper than 30 minutes & Ze3 \\
\hline \multirow[t]{5}{*}{ Storage Location } & Less than $1 \mathrm{~km}$ & Zf1 \\
\hline & Between $1 \mathrm{~km}-3 \mathrm{~km}$ & Zf2 \\
\hline & $3 \mathrm{~km}-5 \mathrm{~km}$ & Zf3 \\
\hline & $5 \mathrm{~km}-10 \mathrm{~km}$ & $\mathrm{Zf} 4$ \\
\hline & Upper than $10 \mathrm{~km}$ & Zf5 \\
\hline
\end{tabular}

Room 7 for develops Port Competitive Assessment (PCA) and Priorities Port Requirement for Improvement (PPR). These PCA and PPR to get target value and scale up factor.

Fig. 5. The list of technical descriptors.

\section{RESULT}

What did us learned from QFD (See Fig. 6):

1) Smooth gate system (Y4) is highly correlated with control of vehicles for all modes (Y6).

2) Trucking efficiency improvement (Xa2) has moderate influenced by material handling facility improvement (Xa4)

3) Smooth gate system (Y4) do not have significant relationship with $\mathrm{Xa} 2$ and $\mathrm{Xa} 4$.

4) $\mathrm{Xa} 2$ and $\mathrm{Xa} 4$ are able to influence the control of vehicles for all modes (Y6).

5) Berth size $(\mathrm{Zb})$ has most significant influence to labour and machine utilization, material handling facilities (Xa4) transportation and trucking efficiency. 
6) Labour and machine utilization (za) has potential to improve trucking efficiency.

7) Stockpile location can affect trucking efficiency.

8) Lorry in transportation for moving cargo is determined as the most relevant factor in the improvement of Kuantan Port.

9) Considerations also need to be addressed on labour and machine utilization followed by berth size expansion, trucking efficiency and stockpile location.

10) Material handling seems to be least important focus compared to others.

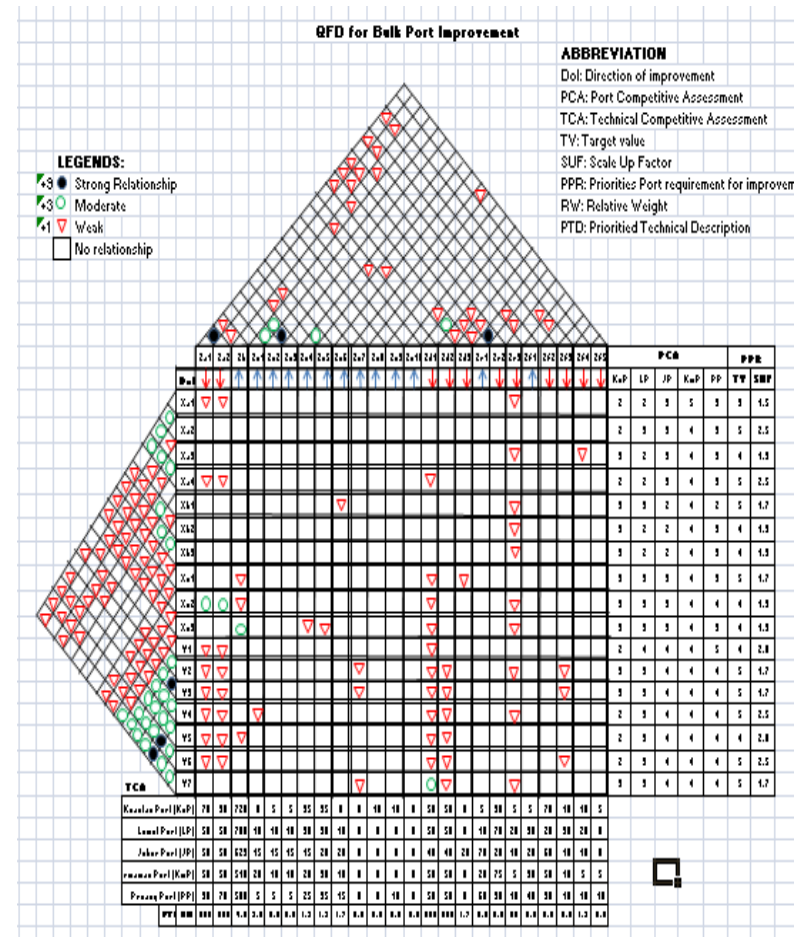

Fig. 6. Complete QFD.

\section{CONCLUSION}

QFD especially in HOQ is an effective management tool in customer expectations are used to drive the design process or to improvement in service industries. It's give the solution to port management WHATs and HOWs aspects must be improved.

\section{REFERENCES}

[1] UNCTAD, Review of Maritime Transport 2011, United Nations Publication, New York and Geneva, 2011.

[2] G. Lodewijks and D. L Schott, "Dry Bulk terminal expansion or redesign," Port Technology International, pp. 87-94, 2011.

[3] J. F. Ding, "Using fuzzy AHP to investigate key factors influencing the quality of service delivery system for port of Kaohsiung," Adv. Fuzzy Sets Syst., vol. 1, no. 1, pp. 63-81, 2006.

[4] J. F. Ding and G. S. Liang, "Application of fuzzy MCDM to evaluate key capabilities for port of Kaohsiung," Maritime Quart, vol. 15, no. 1, pp. 19-37, 2006.

[5] J. F. Ding and G. S. Liang, "Application of fuzzy QFD to identify solutions of service delivery system for port of Kaohsiung," Quality \& Quantity, Springer, no. 1, pp. 553-570, 2009.

[6] ASEAN Port Association, APEC Transportation Working Group, 2002 - 2006, 2008.

[7] K. Crow. (2002). Customer-focused development with QFD. [Online]. Available: http://www.npd-solutions.com/qfd.html

[8] WaveLength Port Authority, 2004.

[9] T. Notteboom and P. Verhoeven, "The awarding of seaport terminals to private operators: European practices and policy implications," Eur. Trans. Trasp. eur., vol. 45, pp. 83-101, 2010.

[10] T. E. Notteboom, P. Verhoeven, and M. Fontanet, "Preferred scale of container terminals," Research in Transportation Economics, vol. 32, no. 1 , pp. $71-80$

111] Z. Zakaria, Statistik Pengurusan Edisi Pertama, Sintok: UUM, 1999.

[12] C. A. Moser, Survey Methods in Social Investigation, Heinemann, London, 1967.

[13] Y. P. Chua, Statistik Penyelidikan Lanjutan II: Ujian Regresi, Analisis Faktor dan analisis SEM. Buku 5, Kuala Lumpur: McGrawHill (Malaysia) Sdn Bhd, 2009a.

[14] C. A. Geffen and S. Rothenberg, "Suppliers and environmental innovation," The Automotive paint process International Journal of Operations and Production Management, vol. 20, no. 2, pp. 166-186, 2000.

[15] J. Hall, "Environmental supply chain dynamics," Journal of Cleaner Production, vol. 8, no. 6, pp. 455-471, 2000.

[16] C. F. Nachmias and D. Nachmias, Research Methods in Social Sciences, New York: St Martin's Press, 1992.

[17] MIDA. (2011). [Online]. Available: http://www.mida.gov.my

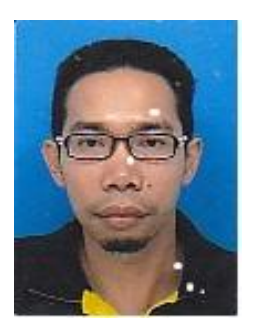

Muhammad Ashlyzan Bin Razik graduated with business management degree from North University Malaysia, 2001. He then completed a master of education in College University Tun Hussin Onn, Malaysia, (2003). He is currently completing doctor of philosophy $(\mathrm{PhD})$ in simulation and modeling of supply chain. Ashlyzan has worked at various practices in Malaysia and since 1995. Some of his current professional activities working as lecturer in business and logistic at Politeknik Sultan Haji Ahmad Shah, Kuantan. Pahang, he is a part time lecturer for Islamic management at Open University Malaysia and also a business area at KFORCE, Malaysia. He is examiner for management and business examination for Private Institutes. He is also conducted a research in entrepreneur for Government Institute. 